\title{
Literature Review on Lightning Protection of Wind Turbine Blades
}

\author{
Ruifeng Wang, Xiaojin Fu* and Feng Xiao \\ Shanghai Dianji University, ShangHai, China \\ *Corresponding author
}

\begin{abstract}
Wind energy is renewable and clean energy which has the most mature technology and the development conditions. Wind power generation provides the basis for the harmonious development between man and nature. The wind turbine is working under the natural environment, as a result, it is inevitable to be influenced by natural disasters. With the increase of wind power generation capacity and wind farm scale, the harm of lightning to the safe operation of the wind motor is becoming more and more serious. Wind turbine blade is one of the most vulnerable parts of the damage of lightning. Domestic researches about this are rare. Based on a large number of foreign research materials, the author analyzes the mechanism of lightning damage to wind turbine blades and classify several effective lightning protection measures of blade. It is helpful for the domestic wind power plant to carry out the effective protection of the wind turbine blade.
\end{abstract}

Keywords-windturbine; Wind Trubine Blades; lightning protection measures

\section{INTRODUCTION}

With the increase of blower capacity, wheel hub height also increased from $50 \mathrm{~m}$ to more than $150 \mathrm{~m}$, a blade is $30 \mathrm{~m}$ long, plus, wind turbines are generally installed in open area or the top of the mountain, it has more chances to be struck by lightning [1]. In order to test the fan blade structure and lightning safety, a series of simulation tests are conducted by Danish researchers in the laboratory. Studies have shown that three parts: (1) the roots, materials are generally composites or carbon fiber reinforced composite materials. metal structure; (2) the case, the materials are fiber glass; (3) keel (stiffener or strengthen box), Materials are generally made of glass fiber reinforced.

Regardless of the blade is made of wood or glass fiber, or a leaf is wrapped in electrical conductor, the lightning strike by the insulation material composition of the blade can be interpreted as a result of the use of a period of time after the leaves will contain pollution and water. The high voltage test also shows that when the blade sprayed by brine, the blades of an insulating material are similar to a conductor that can be easily struck by lightning. Another explanation is that the blade itself is the channel of the thunder and lightning strikes the fans because the discharge of the surface of the blade is much easier than the breakdown of the air discharge. The extent of the damage depends on the form of the blade. The full insulated blade does not reduce the risk of being struck by lightning. On the contrary, it will increase the number of damage. The study also showed that in most cases the area struck by lightning concentrated in the blade tip (or surface) on the back. The research results promote the rapid development of lightning protection design of blade. In order to protect the blade, the lightning arrester is installed on the tip of the blade to intercept lightning, then, through the inner cavity of the vane deflectors to make the lightning current into the earth, Such lightning protection system design is simple and effective. If the flash device or the lead off line breakdown, it only needs mechanical switch.

\section{Lightning Damage To The FAn Blades}

According to the different braking mechanism, four typical blade structures are given in figure 1 .

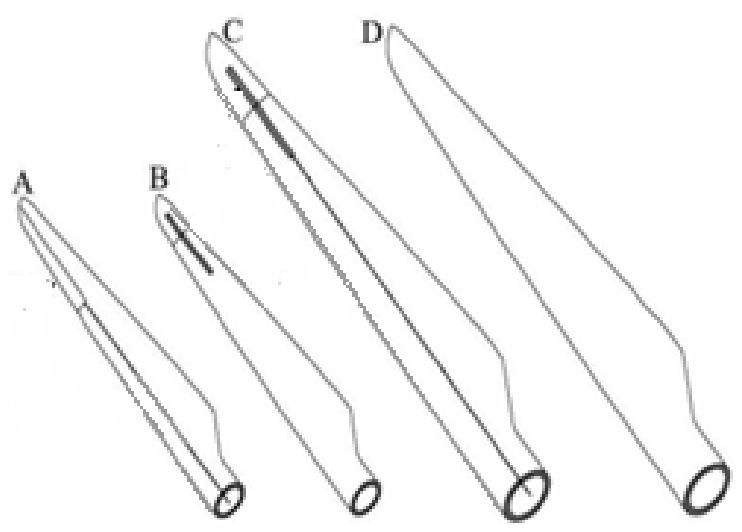

FIGURE I. FOUR TYPICAL STRUCTURES OF BLADES.

A type blade with flap in front of external (aileron) is made as the braking device. For A type blade, lightning strike point often occurs on the flap of stainless steel hinge, so it will cause serious damage frequently. This is due to the manipulation of the wire section flap is too small which usually not enough to be used for the transmission of lightning current.

B type blade adopts the tip brake structure, and most of the lightning strike point occurs in the range of the most sophisticated tens of centimeters or at the edge of the skip axis. [2] When a lightning strike at the edge of the support shaft skip with metal arc formed between the fixed flange of blade root, it will cause catastrophic damage to the blade.

Type A and type B usually used for about $100 \mathrm{~kW}$ of the old style fan. Type $C$ is a new type of blade. It has a tip brake structure which is controlled by a steel wire. Type D is made of insulating materials. 


\section{Lightning Protection Measures of Blade}

Lightning protection's main idea is to conduct lightning current from the lightning strike point safely to the ground wheel, so as to avoid the formation of lightning arc in the blade. This can be achieved by installing metal conductor on the outer surface or inside to transmit lightning current from the lightning strike point to the blade root. Another way is to add conductive material on the surface of blade, thus, the blade itself could transmit lightning to the root of blade.

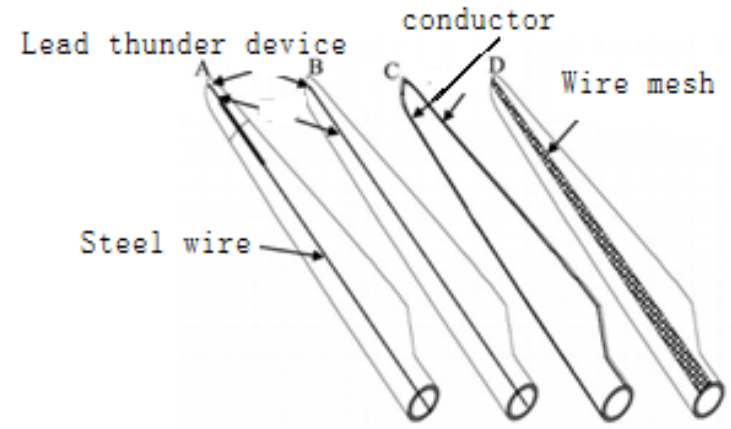

FIGURE II. MODERN LIGHTNING PROTECTION MEASURES OF BLADES

Picture 2 is Lightning protection system installed on the blade surface or inside. It shows three kinds of lightning protection system for the grounding device and the lead wire by connecting to the root of blade. They are type A, type B and type C. type A and type B will put metal conductor inside blades as the lead wire. A metal device is fixed at the tip of the blade surface as a grounding device. [3] It penetrates the blade and connects with the conductor. This kind of protection system is also common in the aviation aircraft. The lead wire conductor placed in the blade is capable of transferring the lightning current from the tip of the blade tip to the root of the blade. For the blades with a tip brake structure, wire used for controlling the blade tip can also be used as a guide line, such as type A. If the blades have no tip brake structure, a copper wire fixed on the wing of the blade can be used as the lead line, such as type B.

In aviation industry, when the blade surface is changed into electric conduction material, the wing's lightning protection system is add conductive material to the wing's surface so as to reduce the damage to the small area of lightning stroke. The method of adding these conductive materials may be spraying the metal material on the surface directly, or mixed the metal fibers in the outer layer of the composite material, or wire the metal into it, or put the metal mesh on the blade surface directly. Type D in picture 2 is a lightning protection system that makes the surface conductive. [4]This kind of protection system put the metal mesh under the surface of the blade. Some blades' tops are made of metal materials or covered with a layer of metal. First, a stainless steel Installed on the top of blade, then, the copper wire mesh will be attached to both sides of the leaves. Thus, the tip and the bottom could be connected as a group of conductors. The wire net not only can be used as a lead line can also guide the lightning from the top to the ground. Usually can be divided into direct lightning, lightning discharge induction thunder and lightning invasion wave and four spherical thunder. Mainly introduces the first two under the protection of lightning discharge. (1) direct lightning protection: is to protect the building itself is not affected by lightning damage, and weaken the lightning when discharged into the huge lightning current along the building when the various influence on building interior space. Direct lightning protection mainly adopts independent lightning rod (small building).Construction technology of lightning rod, lightning measures should be adopted, belt, mesh, downlead, equalizing ring, equipotential, grounding body. (2) induction lightning protection: measures of thunder clouds occur from flash, flash, flash among clouds, cloud produced in the structure of the various kinds of metal pipe, line lightning impulse function limit, thus to protect the safety of personnel in the building and all kinds of electrical equipment. Measures should be according to the actual circumstances of the equipment, in addition to have good grounding and wiring system, safe distance outside, but also according to the power lines, power cables, signal lines, telecommunication lines, feeder installation of lightning arrester and the shielding measures accordingly.

\section{The InTROduction OF AN INVENTION PATENT}

\section{A. Technical Solutions}

As shown in figure 3 is the Profile view of fan blade. Picture 1 is shell, picture 2 is blade motherboard and picture 3 is groove. On the main board, there is a groove with cable which could guide the lightning. One end of the cable is grounded and the other end is connected with the flash. The gap between the blades and the conducting cable sealed up by ECA.

\section{B. The Optimization Effect of the Scheme}

Blade surface is changed to electric conduction material in the aviation industry and the wing's lightning protection system is often added conductive material on the wing's surface in order to reduce the damage to the small area of lightning strike. [5]The method of adding these conductive materials may be spraying the metal material on the surface directly, or mixed the metal fibers in the outer layer of the composite material, or wire the metal into it, or put the metal mesh on the blade surface directly.

Inside the blade, the distribution of water vapor is different according to different materials and parts. Under the action of high temperature by lightning and internal electric arc, the imbalance within the material will cause a sharp expansion and the blades will be damaged: such as cohesive crack, leakage, edge crack, longitudinal crack, lubricating oil. It means the partial or full damage. An arc form by Lightning in the wind turbine blade will cause the most serious damage. Arc may occur in a cavity that is filled with air or along the inner surface. Wind turbine blade is one of the most vulnerable parts of the damage of lightning. The conductive cable is not exposed by conductive adhesive and the using of conductive adhesive is equivalent to a conductive circuit which makes the conductive effect better. 


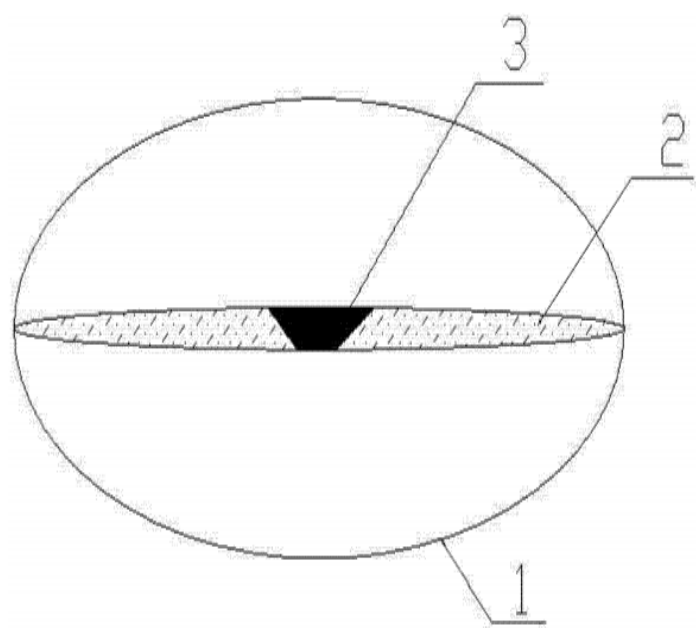

FIGURE III. THE PATENT PROFILE VIEW.

1: blade shells 2: blade motherboard 3: groove

\section{CONCLUSION}

Wind turbine blade is one of the most vulnerable parts of the damage of lightning. On the basis of a large number of research data, this report analyzes the mechanism of the damage caused by lightning strike, sums up several lightning protection measures of the blades of the wind turbine and introduces one invention patent. At the same time, the author introduces a simulated experiment about the blade struck by lightning in Japan. It shows that the installation of lightning arrester can effectively intercept lightning in the blade tip. Also, if the lightning arrester is roughly the shape of a disk which installed on the surface of the blade, it will engender electric arc inside.

\section{REFERENCES}

[1] Amy L. The utilization of wind energy[R]Technical Report2012, 14(3):111-113.

[2] Wind turbine operation: causes for failure[R]http: / /euw inet.iset.unikasse.lde.

[3] Micheal R. Wind turbinelightning protection. project[R]Technical Report 2011,11(5):13-24.

[4] Shunji Mari, Kazauhiko Yamamoto.Historical Review of OCR Research and Development. [J] Processing of IEEE. (2011) 1029-1057.

[5] BehroozV,HassanA. Wind turbine generator systems.[J]Transaction on Electrical Power,2014,15(5):413-424. 